\title{
Is there an engineering approach for the transition to a sustainable hydrogen economy?
}

\author{
M. F. Platzer \\ AeroHydro Research \& Technology Associates, USA
}

\begin{abstract}
In the paper "Assessing Dangerous Climate Change: Required Reduction of Carbon Emissions to Protect Young People, Future Generations and Nature" published in PLOS One, 3 December 2013, James Hansen and thirteen co-authors warn about the possibility of irreversible climate change and its catastrophic effect on the world population. The question, therefore, needs to be answered as to whether the global warming phenomenon is becoming irreversible due to the complex global systems dynamics involved in satisfying the global energy demand. In this paper, the arguments that tend to support the irreversibility hypothesis are analyzed first. It is then shown that there may still be time to reverse the warming trend by tapping into a hitherto unexplored energy resource, namely the wind over vast ocean areas. The key to a complete conversion to emission-free power production, therefore, may be a fleet of large sailing ships equipped with hydro-turbines and electrolysers to split the seawater into hydrogen, which is then compressed and shipped back to shore. This "energy ship concept" therefore requires no new technology development effort, thus strengthening the argument that a transition to a sustainable hydrogen economy is possible.

Keywords: complex systems, climate change, ocean winds, renewable energy production, sailing ships.
\end{abstract}

\section{Introduction}

The rapid world population increase from two billion in 1930 to seven billion, the carbon dioxide increase from 280 parts per million to $400 \mathrm{ppm}$ and the sea level rise by $20 \mathrm{~cm}$ are strong indicators, among other empirical evidence, that the environmental conditions on planet Earth are undergoing rapid changes. A consensus has developed in the global scientific community [1] that the observed 
changes are mostly caused by the switch from burning wood to coal, oil, and natural gas. As a consequence, according to MacKay [2], during the past 250 years the energy consumption rose from about $20 \mathrm{kWh}$ per day per person to about 200 to $300 \mathrm{kWh}$ for persons living in the industrialized countries. Most of this dramatic increase in energy production was achieved by the burning of fossil fuels. It caused the emission of some 370 gigatons of carbon dioxide which stays in the atmosphere for centuries because of its very slow decay rate [2]. The physics and thermodynamics of the global warming are well understood. Although the amount of $\mathrm{CO}_{2}$ in the atmosphere is very small an increase has a significant effect on the energy balance. According to Hansen et al. [3] Earth's energy imbalance currently is approximately $+0.5 \mathrm{~W} / \mathrm{m}^{2}$. In mid-2013 the $\mathrm{CO}_{2}$ level was 395 parts per million (ppm). In the meantime it broke through the $400 \mathrm{ppm}$ level. To restore energy balance the $\mathrm{CO}_{2}$ level must be reduced to $360 \mathrm{ppm}$ if the imbalance is $0.5 \mathrm{~W} / \mathrm{m} 2$. Therefore a goal of reducing the $\mathrm{CO}_{2}$ level to $350 \mathrm{ppm}$ appears to be the right amount in order to stabilize the Earth's climate. According to Hansen et al. [3], due to the slow decay of the $\mathrm{CO}_{2}$, it will take until 2070 to decline to $350 \mathrm{ppm}$ if the emission were totally stopped in 2015 and until 2300 if it is stopped in 2030. A more realistic scenario is to assume yearly global $\mathrm{CO}_{2}$ reductions. If emissions reduction had begun in 2005, a 3.5\% yearly reduction would have achieved 350 $\mathrm{pm}$ in 2100 . Delay of global emissions reduction until 2020 requires a yearly reduction rate of $15 \%$ to achieve $350 \mathrm{ppm}$ in 2100 .

\section{Possibility of irreversible climate change}

According to Hansen et al. [3], the Antarctic and Greenland ice sheets may start to disintegrate at a rate that cannot be stopped because ocean warming will persist for centuries making it impossible to stop the melting process. As a consequence, there exists the possibility that the sea level will rise by several meters with catastrophic effects on human civilization. In this paper we address the question whether it is technically feasible to meet the goal of implementing a $15 \%$ yearly $\mathrm{CO}_{2}$ reduction starting in 2020 .

\section{Considerations on complex systems dynamics}

As is well known, any dynamical system, once set in motion, keeps moving by virtue of its acquired momentum. Any changes require the application of forces strong enough to effect a change. Hansen et al. [3] explain in detail the climate forcings and feedbacks that can be expected for various greenhouse gas emission scenarios. They emphasize the importance of the system inertia. Barnosky et al. [4] also warn of the possibility of approaching a state shift in Earth's biosphere. Such a shift can be caused by threshold effects making it impossible to return to the previous system state. Unfortunately, threshold-induced state shifts are difficult to anticipate because the critical threshold value is not known in advance. However, it is apparent from these two papers that continued climate forcing by means of continued $\mathrm{CO}_{2}$ emission can lead to an irreversible global climate state shift. Furthermore, there is a second inertia effect which needs to be taken into 
account. This effect has to do with the resistance of the global population to convert from fossil-based to emission-free energy production because global fossil-based energy production comprises $80 \%$ of the total production. The capital investments in fossil-based energy production and the need to amortize these investments cause a system inertia which strongly resists abrupt change. Collective global legislative action to impose and enforce $\mathrm{CO}_{2}$ emission limits on individual countries therefore has been largely unsuccessful. It therefore appears that the system inertia is so large that only strong new forces can produce the emission cuts needed to avert irreversible climate change in time. In the following sections we attempt to elucidate two such forces.

\section{Fear-based system change}

Human history provides many examples that demonstrate the effectiveness of producing rapid change due to conflicts between groups of people. Examples are the changes brought about by the two world wars of the last century. These wars showed that it is possible to mobilize millions of people to unite for a common objective and to motivate or force them to endure incredible hardships in the pursuit of this objective. They also greatly accelerated the development of technical capabilities which otherwise might have taken much longer or might not have been developed at all (for example the atom bomb). This history shows that profound system changes can occur quite quickly in response to events that mobilize a large number of people to unite in collective actions.

\section{Technological response times}

A remarkable feature of this past history is the short time period which was needed to develop and apply a revolutionary new technology. For example:

The Wright brothers flew their first airplane on 17 December 1903. Only fifteen years later at the end of World War I well over 200,000 airplanes had been built and flown by all the adversaries in this war.

The first jet-propelled aircraft was flown in August 1939 and only thirteen years later the first jet-propelled civilian passenger plane was put in service and only eight years later most airlines were switching to jet-propelled flight.

The first supersonic missile was successfully test flown in 1942. Again, only fifteen years later this technology made it possible to launch the first satellite and, only twelve years later, to land two men on the moon.

The lesson to be drawn from this technology history is that it takes only ten to twenty years from the recognition of a new revolutionary technology until its worldwide adoption.

\section{The technological response to climate change}

In the previous sections we concluded that global legal action is quite unlikely to overcome the inertia in the complex climate change system dynamics within the 
next twenty to thirty years. Yet, this is the time span which seems to remain available for effective corrective action before irreversible climate change is setting in. Assuming that the global community can be mobilized to take corrective action by the use of existing or the development of new renewable energy technologies two key questions need to be answered:

a) Are there sufficient renewable energy resources on planet Earth?

b) If so, what are the most promising technologies which ought to be used?

\section{Renewable energy resources}

In a quite comprehensive study, MacKay [2] demonstrated the need to distinguish between the theoretically available and the practically exploitable resources. For example, based on the available wind data one may conclude that $2 \mathrm{~W} / \mathrm{m}^{2}$ is available in the United Kingdom. When multiplied with the population density of $4000 \mathrm{~m}^{2}$ per person one arrives at $8000 \mathrm{~W}$ per person or $200 \mathrm{kWh}$ per day per person. However, it is impossible to cover the whole country with wind turbines. Instead, it is more realistic to assume that only $10 \%$ of the UK land area is available so that land wind power can supply only $20 \mathrm{kWh}$ per day per person. Therefore the UK government has become quite aggressive in developing off-shore wind power where a $50 \%$ larger wind power per unit area of $3 \mathrm{~W} / \mathrm{m}^{2}$ becomes available. For the placement of shallow offshore wind turbines an area of about $40,000 \mathrm{~km}^{2}$ is theoretically available. However, large portions of this area are off-limits for wind farms due to the requirement for shipping lanes and fishing areas. MacKay [2] proposes that at most one third of this area can be used. Therefore shallow offshore wind turbines can contribute perhaps $16 \mathrm{kWh}$ per day per person. Going further offshore into depths between $25 \mathrm{~m}$ to $50 \mathrm{~m}$ opens up another $80,000 \mathrm{~km}^{2}$ and therefore could deliver $96 \mathrm{kWh}$ per day per person if turbines completely filled this area. Again, the need for shipping lanes will reduce this amount to $32 \mathrm{kWh}$ per day per person. Using similar estimates for the other renewable energy technologies (solar thermal, solar photovoltaic, solar biomass, hydroelectricity, wave energy, tidal energy, geothermal energy) MacKay estimates that the renewable energy technologies available in the United Kingdom can contribute approximately $180 \mathrm{kWh}$ per day per person whereas the total energy consumption is $195 \mathrm{kWh}$ per day per person. This would suggest that the renewable energy resources available within the United Kingdom can satisfy the demand. However, this implies maximum development of the available resources. In MacKay's view the opposition to such a development by various interest groups will be so great that only one tenth of the maximum available resources will become available, i.e. $18 \mathrm{kWh}$ per day per person. He suggests that the difference can be made up by importing power from concentrating solar power plants located in North Africa and the Middle East and increasing the use of nuclear power plants. He also concludes that the one billion people living in Europe and North Africa are faced with a similar gap between renewable energy production and consumption and therefore concentrating solar power plants covering a total area of $600 \mathrm{~km}$ by 600 $\mathrm{km}$ will need to be built in North African and Middle Eastern desert areas. He applies the same considerations to the whole world and comes again to the 
conclusion that the exploitation of the relatively high solar power densities in desert areas is needed together with the other low density renewable technologies to satisfy the global energy demand. A desert area of 1000 by $1000 \mathrm{~km}$ will be needed for the concentrating solar power plants to supply every person in the world with $125 \mathrm{kWh}$ per day.

In 2009 Jacobson and Delucchi [5] presented a plan for a sustainable future by proposing to satisfy the global energy demand from wind, water, and solar power by 2030 . To achieve this goal, 490,000 tidal turbines of $1 \mathrm{MW}$ output per turbine, 5,350 geothermal plants of $100 \mathrm{MW}$ output per plant, 900 hydroelectric plants of $1.3 \mathrm{GW}$ output per plant, 3,800,000 wind turbines of $5 \mathrm{MW}$ output per turbine, 720,000 wave converters of $0.75 \mathrm{MW}$ per converter, 1,700 million $3 \mathrm{~kW}$ roof top photovoltaic systems, 49,000 concentrating solar power plants of $300 \mathrm{MW}$ per plant, and 40,000 photovoltaic power plants of $300 \mathrm{MW}$ per plant would be required. They estimate the overall construction cost of such a wind-water-solar (WWS) power generation system to be in the order of $\$ 100$ trillion worldwide.

In 2008 Inslee and Hendricks [6] proposed a crash program modeled after the Apollo lunar landing project to reach the goal of full conversion to renewable power production in the United States. They emphasized the absence of a "silver bullet" and therefore called for the rapid development of all available renewable and nuclear power production technologies.

In 2007 the Google Corporation started to commit significant resources to tackle the global climate and energy problems [7]. The objective was to develop renewable energy sources that would generate electricity more cheaply than coalfired power plants do and to achieve this in years, not decades. As reported by the two Google engineers Koningstein and Fork [7], Google investigated a wide range of innovative technologies, such as self-assembling wind turbine towers, drilling systems for geothermal energy, and solar thermal power systems. However, by 2011 it became clear that this initiative would not be able to deliver a technology that could compete economically with coal, and Google officially terminated the initiative and shut down the related internal R \& D projects. Koningstein and Fork [7] conclude that reversing climate change will require both radical technological advances in cheap zero-carbon energy as well as a method of extracting $\mathrm{CO}_{2}$ from the atmosphere and sequestering the carbon. They summarize their conclusions by stating that they have been unable to identify a disrupting renewable energy technology but they express the hope that perhaps a technology can be found that changes the economic rules of the game by producing not just electricity, but also fertilizers, fuel or desalinated water.

It is apparent from the preceding discussion that concentrating solar power plants located in the world's desert areas are regarded as essential for the provision of sufficient renewable to satisfy the global energy demand. Google even goes so far as to claim that a new disruptive energy technology is needed to make any decisive progress in reducing $\mathrm{CO}_{2}$ emissions. This claim implies the need for significant resources and time to develop this new technology. The question therefore arises whether this conclusion is indeed correct. As is customary in any situation that requires an engineering solution it is imperative to follow strict rules, namely: 
1) Define the problem

2) List the resources available to solve the problem

3) List the possible approaches to solve the problem

4) Prioritize the possible approaches according to probability of success

\section{Problem definition}

We accept the challenge posed by Hansen et al. [3] that the global $\mathrm{CO}_{2}$ emissions need to be reduced each year by $15 \%$ starting no later than 2020 .

\section{Renewable energy resources inventory}

The renewable energy resources available on land or in coastal waters have been catalogued in various comprehensive studies and therefore need not be discussed in this paper. It appears that there are only two additional resources that have received little attention and therefore need to be scrutinized as to their potential for exploitation. They are the high-altitude jet streams and the winds close to the ocean surface far from coastal areas.

As is well known, the Earth's surface creates a boundary layer effect so that the wind speed generally increases with altitude, often resulting in a doubling of the wind speed at an altitude of only a few hundred meters above the surface. This increase in wind power with altitude suggests that it might be attractive to place power generators at altitudes of a few hundred meters from the surface. An even more powerful wind power source exists at altitudes between eight to fifteen thousand meters at latitudes between 30 and 40 degrees in each hemisphere. The average wind speed in these so-called jet streams can be very high, around 40 to $50 \mathrm{~m} / \mathrm{s}$. Jet streams therefore represent an enormous source of wind power since power increases with the cube of the wind speed although the air density decreases by 50 to 70 percent from its sea-level value. The jet streams occur over most industrialized countries in the northern hemisphere and over Australia. Hence these countries "own" their jet streams for potential exploitation.

A second source of wind power is to be found over the oceans. The winds in the northern and southern hemisphere move in mirror images. On each side of the equator the trade winds blow consistently from the East. Further South and North there is a second pair of wind belts with stronger winds that usually blow from the West and therefore are called the Westerlies. Close to the Polar Regions there is a third wind belt with winds from the East, therefore called the Polar Easterlies, which are much stronger than in the other wind belts.

\section{Possible approaches}

Winds at any altitude, but especially at jet stream altitudes, represent an attractive renewable power source. It is therefore not surprising that a number of attempts [8] have been made to mount wind turbines on tethered balloons, aerostats or airplanes or to use tethered rotorcraft. Another possibility is offered by kites that 
are flown downwind of a tether in a figure-eight type loop, thus requiring a considerable amount of air space. The Google Corporation supported the Makani Company [8] to explore this concept and appears to develop it further in-house. However, it is quite clear that the conversion of altitude wind power into electricity is a very challenging technical problem.

The second wind power source is the ocean wind power. Given the fact that seventy percent of the globe's surface is covered by oceans, vast ocean areas are exposed year-round to strong surface winds. The question arises whether this huge wind power resource can be exploited for power generation. The placement of wind turbines on floating platforms relatively far from shore might seem a logical extension of the off-shore wind turbine concept. Turbine size, storm survivability, and power transmission back to shore pose serious challenges, however. Due to the low air density a wind turbine has to have a large air capture area in order to generate, say, five Megawatt at wind speeds of, say, $10 \mathrm{~m} / \mathrm{s}$. In contrast, a hydroturbine is much smaller for the same power output due to the 800 times larger water density, provided the hydro-turbine is exposed to a water stream of, say, 5 $\mathrm{m} / \mathrm{s}$. Furthermore, the survivability challenge can be overcome by mounting the hydro-turbine(s) on a sailing ship. Given today's weather prediction state-of-theart a sailing ship can avoid heavy storm areas. These considerations suggest to use sailing ships in such a way that the electricity produced by the hydro-turbine(s) is fed into electrolysers for the purpose of splitting the sea water into hydrogen and oxygen, and then compressing and storing the hydrogen gas in suitable highpressure tanks. These tanks then are periodically transported back to shore for heating/cooking purposes, for use as transportation fuel or reconversion into electricity in fuel cells or hydrogen-oxygen power plants. It needs to be emphasized that the need for a large air capture area required by wind turbines for direct conversion to electricity has not been eliminated in this "energy ship concept". A large sail area is still required to give the sailing ship sufficient thrust to overcome the hydro-turbine and ship drag. Platzer and Sarigul-Klijn [9] first proposed this concept in 2009 and Platzer et al. analyzed it in more detail in references $[10,11]$.

\section{Prioritization of possible approaches}

Consistent with the problem definition of reducing the global $\mathrm{CO}_{2}$ emission every year by $15 \%$ there are only four approaches which have been proposed to reach this ambitious goal. MacKay [2] stressed the necessity of transmitting power from concentrating solar power plants located in desert areas together with nuclear power in order to supplement the low-density renewable power available in densely populated areas. Jacobson and Delucchi [5] proposed the WWS (windwater-solar) initiative which again relied heavily on the development of solar power, in particular concentrating solar power plants in desert areas. Inslee and Hendricks [6] proposed an Apollo-type renewable energy development program, but stressed the fact that there seemed to be no "single bullet" technology which might be able to revolutionize the conversion to renewable energy production. All these proposals are based on the assumption that only land-based or off-shore 
based renewable energy technologies are feasible for development. In contrast, the energy ship concept proposed by Platzer and Sarigul-Klijn [9] (Figure 1) stresses the option of supplementing the land-based and off-shore based renewable power production by exploiting the ocean wind power.

Given the fact that renewable power currently contributes only seven percent to the total global power production there is justifiable doubt that the approaches proposed by MacKay [2], Jacobson and Delucchi [5] and Inslee and Hendricks [6] can achieve the required annual $15 \%$ emission reductions. Although technically feasible, the political, financial and legal hurdles which need to be overcome in each country and the difficulties of reaching agreement about burden sharing between developed and lesser developed countries make it unlikely that the pace of land-based or off-shore based renewable power generation can be accelerated using technologies that are perceived as too threatening to powerful special interests or too financially burdensome for the citizens of most countries. This consideration raises the question whether the energy ship concept can make a difference in this assessment.

\section{The energy ship concept}

According to Platzer et al. [9, 10,11] it is technically feasible to build sailing ships of a size comparable to modern container ships which can produce about 2 or 3 MW of electric power to be fed into electrolysers for conversion of sea water into hydrogen and oxygen. A major advantage of this concept is the conversion of wind power into storable energy in the form of high-pressure hydrogen. Another advantage is the much higher capacity factor available to sailing ships operating in wind-rich ocean areas as compared to land or off-shore based wind turbines. These two features make it possible to implement the "power-to-gas" concept whereby the intermittency problem of conventional wind and solar power plants can be overcome by making hydrogen available on demand. A further advantage is the ability to operate the energy ships in international ocean areas so that any country can send its fleet of energy ships to these areas without having to ask for permission. Therefore the legal obstacles encountered by renewable energy development projects within a country's national boundaries are avoided.

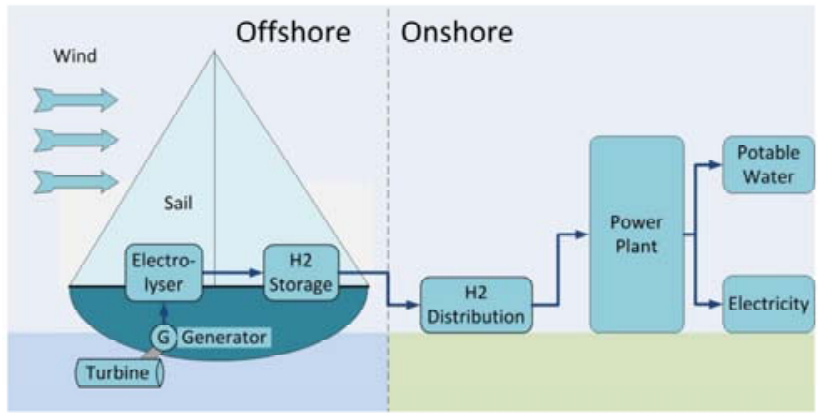

Figure 1: Overall system scheme of the energy ship conversion chain. 
The basic energy ship concept is shown in Figure 1. Wind driven sailing ships equipped with hydro-turbines, desalinators, electrolysers and compressors make it possible to produce compressed hydrogen which is stored in high-pressure tanks. These tanks then are transported back to shore for direct use in hydrogen fuel cell cars, for heating and cooking, or reconverted into electricity in fuel cells or hydrogen-oxygen power plants. A welcome by-product of this reconversion process is potable water. As pointed out by Platzer et al. [10], for example, hydrogen-based power production in Australia would make it possible to provide every Australian with $40 \%$ of his/her daily potable water consumption of 177 liter.

Also, it is important to keep in mind that the availability of hydrogen makes it possible to produce carbon-neutral jet fuel. In recent years, Willauer et al. [12] and Eisaman et al. [13] have been studying the possibility of replacing the conventional jet fuel by a synfuel manufactured from hydrogen and carbon dioxide extracted from sea water.

\section{Energy ship development and cost estimate}

It is remarkable that the implementation of the energy ship concept requires no new technology. Sailing ships, hydro-turbines, desalinators, electrolysers, compressors, and hydrogen tanks are all well-known commercially available technologies. This means that no innovative lengthy development is required, although it will be desirable to incorporate the latest advances in each technology area, such as rigid wings instead of conventional sails and hydrofoil supported ships to minimize the ship drag. It also means that the energy ship concept can be introduced at initial investment levels in the order of millions of dollars (instead of billions of dollars as required for nuclear power plants, for example) with only a few prototype ships to demonstrate total system performance and to validate cost estimates. Current best estimates are costs similar to off-shore turbine costs, hence $\$ 5000 / \mathrm{kW}[14]$. A $5 \mathrm{MW}$ ship therefore is estimated to cost $\$ 25,000,000$. Accounting for the losses in producing the hydrogen, transporting it to shore and reconverting it to electricity it is prudent to assume an efficiency of only 33 percent.

\section{Cost estimate of annual global emission reduction}

Global power consumption is estimated at $15 \mathrm{TW}$, hence an annual $15 \%$ reduction requires the annual global renewable power production of $2.25 \mathrm{TW}$. Assuming that only one third of the $5 \mathrm{MW}$ power output per ship is delivered to the consumer, i.e., 1.67 MW, approximately 1,500,000 ships are needed if one assumes a capacity factor of 90 percent. The cost of the total fleet of energy ships therefore is likely to be approximately $\$ 37.5$ trillion. The total power consumption of the United States is approximately $2.5 \mathrm{TW}$, hence 250,000 ships would have to be built and operated per year to contribute to the goal of global emission stabilization. The actual number could be significantly lower if the contributions of other renewable energy technologies and of nuclear power plants are taken into account. 


\section{Is global warming unstoppable?}

The complex system which has been built up over the past two hundred years to provide seven billion people with food and industrial products depends to eighty percent on fossil-based power production. The inertia in this system therefore makes it quite resistant to the rapid change required to prevent irreversible climate change. However, this conclusion may be premature. There can be no doubt that the global renewable resources are quite sufficient to produce the required global renewable power if the ocean wind power is included. Furthermore, as pointed out above, the adoption of new technologies occurs amazingly fast once its advantages are fully recognized. Sailing ship based renewable power production is a "new" technology which has the potential to revolutionize global power production. It is a "new" technology only in the sense that it requires a new way of thinking about power production, namely that it is possible to move the power plant relative to the stationary air or water. The energy ship concept described in this paper is the logical extension of the off-shore wind turbine technology. Although two to three times more expensive than on-shore turbines the use of off-shore turbines enables the capturing of higher wind speeds than available on land. However, they still have the disadvantage of variable power output due the wind intermittency close to shore. Their capacity factor therefore is around forty percent. In contrast, energy ships can operate in wind-rich ocean areas yielding capacity factors of eighty or ninety percent. Furthermore they deliver storable energy in the form of pressurized hydrogen. Yet, the energy ship technology requires no new system components because sailing ships, desalinators, hydro-turbines, electrolysers, compressors and tanks are readily available obviating the need for lengthy technology development projects.

The implementation of the energy ship concept therefore will depend on the same "fear or greed" motivations which caused the introduction and rapid development of revolutionary technologies in the past. As to "fear", it remains to be seen whether the fear of the impact of climate change on the present and future generations will spread sufficiently rapidly from a relatively small group of scientists and environmental activists to the population at large in various countries to generate worldwide governmental support for a fifteen percent annual emission reduction program. Climate change is unlikely to generate Pearl Harbor, Sputnik or 9/11 type shocks which cause an abrupt attitude change. However, such an attitude change may well start in local areas where it becomes obvious that the continued generation of pollution leads to intolerable living conditions. Example are cities such Beijing among others. The second major motivation for the introduction of new technologies is "greed", i.e., the prospect for handsome returns on capital investment. As mentioned by Koningstein and Fork [7], the Google Corporation was looking for reliable zero-carbon energy sources so cheap that the operators of power plants and industrial facilities have an economic incentive to switch to renewable power production. In particular, Google was looking for a technology that would change the economic rules of the game by producing not just electricity but also fertilizer, fuel, or desalinated water. Koningstein and Fork [7] came to the conclusion that no such disruptive 
technology is in sight, completely ignoring the fact that the energy ship concept delivers exactly this combination of products. The storable hydrogen shipped from the energy ships back to shore can be used directly as fuel for hydrogen-fuel-cell powered surface vehicles and ships, it can be converted into methanol for aircraft propulsion (thereby achieving carbon-neutral aircraft propulsion as advocated by Willauer et al. [12] and Eisaman [13]), it can be combined with nitrogen to produce fertilizers, it can be converted into electricity and potable water in fuel cells and hydrogen-oxygen power plants, and finally the electricity generated on energy ships can be used to extract $\mathrm{CO}_{2}$ from the sea water $[12,13]$.

\section{Summary}

In this paper attention is drawn to the possibility of adding a new renewable energy technology option to the existing renewable energy technologies by exploiting the virtually inexhaustible ocean wind power resources. It is shown that the goal of reducing the $\mathrm{CO}_{2}$ emission each year by fifteen percent can be met by constructing and operating each year between one to one and a half million energy ships at an approximate cost of $\$ 30$ to 40 trillion. Any delays in initiating such a program or reducing the annual percentage reductions increases the danger of triggering irreversible climate change. Hence the coming twenty to forty years will reveal whether the inertia in the complex systems dynamics of fossil-based power generation can be overcome by the introduction of innovative renewable power production methods.

\section{References}

[1] IPCC-Intergovernmental Panel on Climate Change, Fifth Assessment Report 2014.

[2] MacKay, David J.C., 2009, "Sustainable Energy - without the hot air", UIT Cambridge Ltd., PO Box 145, Cambridge, England.

[3] Hansen, J., Kharecha, P., Sato, M., Masson-Delmotte, V., Ackerman, F., Beerling, D.J., Hearty, P.J., Hoegh-Guldberg, O., Hsu, S.L., Parmesan, C., Rockstrom, J., Rohling, E.J., Sachs, J., Zachos, J.C., “Assessing Dangerous Climate Change: Required Reduction of Carbon Emissions to Protect Young People, Future Generations and Nature", PLOS One, DOI: 10.1371/journal.pone.0081648, published December 3, 2013.

[4] Barnosky, A.D., et al., "Approaching a State Shift in Earth's Biosphere," Nature Vol. 486, 7 June 2012, pp. 52-58.

[5] Jacobson, Mark Z. and Delucchi, Mark A., "A Path to Sustainable Energy by 2030”, Scientific American, pp. 58-65, November 2009.

[6] Inslee, Jay and Hendricks, Bracken, “Apollo's Fire - Igniting America's Clean Energy Economy,” Island Press 2008.

[7] Koningstein, R. and Fork, D., "What it Would Really Take to Reverse Climate Change," IEEE Spectrum, posted 18 Nov 2014.

[8] Airborne 2010 Wind Energy Conference, Stanford University, 28-29 September 2010 . 
[9] Platzer, M.F. and Sarigul-Klijn, N., "A Novel Approach to Extract Power from Free-Flowing Water and High-Altitude Jet Streams," Proceedings of the ASME Energy Sustainability Conference, San Francisco, CA, 19-23 July 2009, ES2009-90146 and "Aerohydronautical Power Engineering - Is it the Key to Abundant Renewable Energy and Potable Water?”, University Readers, San Diego, California, 2012.

[10] Platzer, M.F., Lennie, M., Vogt, D. M., "Analysis of the Conversion of Ocean Wind Power into Hydrogen", Proc. World Renewable Energy, Congress, Perth, Australia, July 2013.

[11] Platzer, M.F., Sarigul-Klijn, N., Young, J., Ashraf, M.A., Lai, J.C.S., "Renewable Hydrogen Production using Sailing Ships", J. Energy Resources technology, Vol. 136/021203-1 to 5, June 2014.

[12] Willauer, H.D., Hardy, D.R., Schultz, K.R., Williams, F.W., "The Feasibility and Current Estimated Capital Costs of Producing Jet Fuel at Sea Using Carbon Dioxide and Hydrogen," J. Renewable and Sustainable Energy 4, 033111 (2012).

[13] Eisaman, M.D., Parajuly, K., Tuganov, A., Eldershaw, C., Chang, N., Littau, K.A., " $\mathrm{CO}_{2}$ Extraction from Seawater Using Bipolar Membrane Electrodialysis," Energy \& Environmental Science, DOI: 10.1039/ 2ee03393c, 23 January 2012.

[14] Tegen, S., Hand, M., Maples, B., Lantz, E., Schwabe, P., Smith, A., "2010 Cost of Wind Energy Review," NREL Technical Report NREL/TP-500052920, April 2012. 